\title{
Editorial: Upscaling Low-Carbon Energy Resources: Exploring the Material Supply Risk, Environmental Impacts and Response Policies
}

\author{
Jianliang Wang ${ }^{1 *}$, Fan Tong ${ }^{2,3}$ and Mikael Höök ${ }^{4}$ \\ ${ }^{1}$ School of Economics and Management, China University of Petroleum, Beijing, China, ${ }^{2}$ School of Economics and Management, \\ Beihang University, Beijing, China, ${ }^{3}$ Lawrence Berkeley National Laboratory, Berkeley, CA, United States, ${ }^{4}$ Department of Earth \\ Sciences, Uppsala University, Uppsala, Sweden
}

Keywords: low-carbon energy, material supply, environmental footprints, energy-water-climates nexus, policies

Editorial on the Research Topic

Upscaling Low-Carbon Energy Resources: Exploring the Material Supply Risk, Environmental Impacts and Response Policies

\section{INTRODUCTION}

\section{OPEN ACCESS}

Edited and reviewed by: Simone Bastianoni,

University of Siena, Italy

${ }^{*}$ Correspondence: Jianliang Wang wangjianliang305@163.com

Specialty section: This article was submitted to Sustainable Energy Systems and Policies,

a section of the journal Frontiers in Energy Research

Received: 11 October 2021 Accepted: 25 October 2021 Published: 12 November 2021

Citation:

Wang J, Tong F and Höök M (2021) Editorial: Upscaling Low-Carbon Energy Resources: Exploring the Material Supply Risk, Environmental Impacts and Response Policies.

Front. Energy Res. 9:792797. doi: 10.3389/fenrg.2021.792797
Continued reliance on high-carbon fossil fuels in the face of increasing climate change casts a grand threat for modern society (Le Quéré et al., 2021). The global society has joined forces to address climate change, showcased by the UN Sustainable Development Goals and ambitious efforts to mitigate climate change stated in the Nationally Determined Contributions (NDC) for the Paris Agreement. Major countries have agreed to embark on a transition towards sustainable energy systems, where high-carbon fossil fuels would be replaced by low-carbon alternatives to reach carbon neutrality eventually. Although the development and deployment of low-carbon energy resources and technologies have achieved considerable success in the past decades, the scale to achieve carbon neutrality worldwide requires a rapid upscaling of low-carbon energy resources and technologies at speed unseen in human history (World Economic Forum (WEF), 2019).

The transition to sustainable energy systems is not an easy road, as broad and complex social and environmental implications would emerge during the transition. In particular, material supply risk and environmental impacts are the most significant challenges. In this Research Topic, we selected nine recent studies investigating environmental and social impacts caused by the development of low-carbon energy resources and proposing policy suggestions to address these challenges in the transition towards low-carbon energy systems.

\section{Material Supply Risk}

Raw materials, including heavy-metal elements such as Lithium and Cobalt, are essential inputs for developing low-carbon energy resources and form the bedrock of low-carbon energy systems. The upscaling of low-carbon energy resources and technologies would induce exponential increases in material demands, which has led to uneven price dynamics and elevated supply risks. For example, Liu's work Renewable Energy and Material Supply Risks: A Predictive Analysis Based on An LSTM Model (Liu et al.) points out that improving the energy density of metals plays a crucial role in China's transition to a low-carbon energy system. Furthermore, Hu's work An Explanation of 
Energy Return on Investment From an Entropy Perspective ( $\mathrm{Hu}$ et al.) finds that improving resource extraction efficiency would facilitate renewable energy development. Finally, Wang's work Accounting and Management of Natural Resource Consumption Based on Input-Output Method: A Global Bibliometric Analysis (Wang et al.) presents a systematic review of recent natural resource consumption accounting and management studies. This overview clearly shows the increasing research interest and upward trend of research outputs related to upscaling lowcarbon energy resources.

\section{Environmental Impacts}

The upscaling of low-carbon energy resources and the transition to sustainable energy systems is crucial to address the global sustainability challenges but may also bring unexpected environmental impacts if managed poorly. For instance, natural gas is a low-carbon energy resource when replacing coal but could induce methane leakage, water pollution, and landscape impacts (Qin et al., 2018). Fu's work Identifying and Regulating the Environment Risks in the Development and Utilization of Natural Gas as a Low-Carbon Energy Source (Fu et al.) analyzes the environmental risks in the whole process of natural gas exploitation to utilization and put forward policy recommendations to manage these risks. The water-energy-carbon nexus has attracted increasing interest as these environmental impacts are intertwined, and no single solution could solve it all. Li's work Water Use for Energy Production and Conversion in Hebei Province, China (Li et al.) quantifies the relationship between energy production and water consumption in a Chinese province in the context of three future emissions reduction scenarios. On the other hand, well-designed low-carbon energy systems have the potential to mitigate carbon emissions as well as other environmental impacts. Xue's work Environmental Benefit and Investment Value of Hydrogen-Based Wind-Energy Storage System (Xue et al.) estimates the environmental benefits of hydrogen-based wind-energy storage systems, promoting renewable energy integration.

\section{REFERENCES}

Le Quéré, C., Peters, G. P., Friedlingstein, P., Andrew, R. M., Canadell, J. G., Davis, S. J., et al. (2021). Fossil CO2 Emissions in the post-COVID-19 Era. Nat. Clim. Change 11, 197-199. doi:10.1038/s41558-021-01001-0

Qin, Y., Tong, F., Yang, G., and Mauzerall, D. L. (2018). Challenges of Using Natural Gas as a Carbon Mitigation Option in China. Energy Policy 117, 457-462. doi:10.1016/j.enpol.2018.03.004

World Economic Forum (WEF) (2019). The Speed of the Energy Transition: Gradual or Rapid Change. Geneva, Switzerland: World Economic Forum. Available at https://www3.weforum.org/docs/WEF_the_speed_of_the_energy_transition.pdf.

Conflict of Interest: The authors declare that the research was conducted in the absence of any commercial or financial relationships that could be construed as a potential conflict of interest.

\section{Response Policies}

Researchers have investigated response policies to support the lowcarbon energy transition to address the material supply risks and the environmental impacts that may impede the upscaling of lowcarbon energy resources. Wang's work China's Energy Transition Policy Expectation and It's $\mathrm{CO}_{2}$ Emission Reduction Effect Assessment (Wang et al.) estimates carbon emissions reductions from China's energy transitions. Zhang's work Analysis of Performance Deviation of Wind Power Enterprises in China (Zhang and Qi) disentangles the impacts of policy measures and market conditions in the dynamics between carbon reduction efficiency and the financial performance of wind power enterprises. Finally, Hu's work The Impact of Policy Intensity on Overcapacity in Low-Carbon Energy Industry: Evidence From Photovoltaic Firm ( $\mathrm{Hu}$ et al.) investigates the overcapacity issue (i.e., the bust-and-boom cycle) in the photovoltaic industry in China and examined the role of government subsidies and policies in the development of the low-carbon energy industry.

\section{CONCLUSION}

A rapid and large-scale upscaling in developing and deploying low-carbon energy resources and technologies is essential to address climate change. Findings from studies in this Research Topic would help industry and governments better understand and manage the material supply risks and environmental impacts in the process of upscaling low-carbon energy resources. As highlighted by the selected studies, cross-discipline experts and practitioners need to work together to address the multidimensional challenges in the transition to sustainable energy systems towards carbon neutrality.

\section{AUTHOR CONTRIBUTIONS}

All authors listed have made a substantial, direct, and intellectual contribution to the work and approved it for publication.

Publisher's Note: All claims expressed in this article are solely those of the authors and do not necessarily represent those of their affiliated organizations, or those of the publisher, the editors and the reviewers. Any product that may be evaluated in this article, or claim that may be made by its manufacturer, is not guaranteed or endorsed by the publisher.

Copyright (c) 2021 Wang, Tong and Höok. This is an open-access article distributed under the terms of the Creative Commons Attribution License (CC BY). The use, distribution or reproduction in other forums is permitted, provided the original author(s) and the copyright owner(s) are credited and that the original publication in this journal is cited, in accordance with accepted academic practice. No use, distribution or reproduction is permitted which does not comply with these terms. 